\title{
Radio frequency peak and average power density from mobile base stations in Ekiti State, Nigeria
}

\author{
Ilesanmi B. Oluwafemi ${ }^{1}$, Adedeji M. Faluru' ${ }^{2}$, Tayo D. Obasanyo ${ }^{3}$ \\ ${ }^{1,2}$ Department of Electrical and Electronic Engineering, Ekiti State University, Nigeria \\ ${ }^{3}$ Department of Computer Engineering, Ekiti State University, Nigeria
}

\section{Article Info \\ Article history: \\ Received Oct 29, 2019 \\ Revised Apr 12, 2020 \\ Accepted Jun 23, 2020}

\section{Keywords:}

Base station

Electromagnetic radiation

Power density

Radio frequency

Spectra

\begin{abstract}
The ever-increasing number of mobile telecommunication base station as a result of increasing demand for broadband applications has raised a growing concern and worry over the health implications and safety of the radiations from these base stations by the resident of Ekiti State and Nigeria in Nigeria. Measurement of radio frequency was conducted in this research in order to study the electromagnetic field radiation level in Ekiti State Nigeria. Investigation was conducted with the four available mobile operators with the three sub-frequency band viz $900 \mathrm{MHz}, 1800 \mathrm{MHz}$ and $2100 \mathrm{MHz}$. The power density of radio frequency radiation was estimated through measurement with the aid of A 3-axis RF radiation strength meter TM-196 and handheld spectrum analyzer model NA-773, 144/430. The peak and average power density was computed using the method of theoretical calculation and the safety distance from the antennas were estimated. The measured and the calculated values were compared with the international commission on non-ionizing radiation protection (ICNIRP) standard for public and occupational exposure level. Results show that the radiations from the base stations adheres to the standard provided by ICNIRP.
\end{abstract}

This is an open access article under the CC BY-SA license.

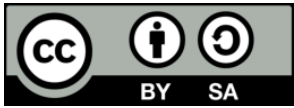

\section{Corresponding Author:}

Ilesanmi Banjo Oluwafemi,

Department of Electrical and Electronic Engineering,

Ekiti State University,

Ado Ekiti, Nigeria.

Email: ibto75@gmail.com

\section{INTRODUCTION}

The recent advances in mobile communication has led to increased broadband applications [1-4]. With the increasing broadband applications, the mobile subscribers are demanding for better coverage, fast speed of network and improved quality of service. The networks operators have been employing cell splitting and erection of new base stations leading to increase mobile base stations in a bid to meet the demand of the subscribers. The increasing mobile telecommunications infrastructures has generated worries among people over the possible adverse health effects from exposure to radio frequency (RF) electromagnetic radiation (EMR) emanating from the mobile base station antennas [5].

Nigerian communication commission (NCC) is the body charged with the responsibility of monitoring the level of radiation from the base station in a bid to enforce compliance to international standards on limits of radiations. Fulfilling this function, NCC monitors RF-EMR levels in the towns and cities to enforce the exposure limit as set by international commission on non-ionizing radiation protection (ICNIRP) [6]. The forces exerted on an electric charge which is known as electric field (E) is expressed in Volt per meter $(\mathrm{V} / \mathrm{m})$ [6]. This electric field strength is the derived quantity which is measured in $\mathrm{V} / \mathrm{m}$ unit and $\left(\mathrm{W} / \mathrm{m}^{2}\right)$ and used for the reference level [7]. Exposure to RF radiation is classified into general public and 
occupational exposure [8]. Those professionals that work with microwave equipments and are often exposed to multiple RF radiation are those classified as occupational [9], while the public who got exposed to RF radiation by the usage are the public exposure. There are however guidelines from the regulating authorities to limit the power density of the RF radiations in the public in a bid to avoid the adverse health effect [10].

The local authority in Ekiti State is finding it very challenging in giving information to the resident in Ekiti State about the mobile base station adherence to the guidelines provided by the ICNIRP. Dwellers are unaware and unsure about their safety from the multiple radiations from the base stations towers as there is no information about their adherence to the standards set by the FCC, IEEEE and the ICNIRP. Many presentations on the media about the safety of the dwellers have been made to allay the fears and worry of the people.

Some studies were carried in [11-17] to confirm the radiation level from mobile base stations and compared with the standard set by ICNIRP. Most of the locations confirmed that the radiations are within the safety level as set by ICNIRP. In [18], measurement was conducted around the base station of some mobile stations and also in [19-21], several measurements were conducted in Sweden in a bid to confirm the safety from these radiations. However, all these were conducted outside the region of concern and there are known information about the adherence of the network operators to the limit set by ICNIRP and such nothing can be said about the safety of the dwellers from the RF radiations. In this experiment three locations in Ekiti state were selected representing the urban, suburban and rural areas in Ekiti State Nigeria to study the RF radiation from the erected base stations. Measurements of $E$-field strength or power density were conducted in Ado-Ekiti; Ifaki-Ekiti, and Iye-Ekiti from base station operation at 900, 1800, and $2100 \mathrm{MHz}$ respectively.

\section{EXPERIMENT SETUP}

Handheld spectrum analyzer model NA-773, 144/430 MHz in fill mode was used to measure the frequency. The measurements taken by the spectrum analyzer were recorded with the spectral scans. A fixed antenna (Probe) was mounted on the spectrum analyzer and automated mobile measurements were made, whilst walking around the GSM base station under survey. A 3-axis RF radiation strength meter TM-196 was also used to measure the detailed RF power density values in $\mu \mathrm{W} / \mathrm{m}^{2}$ and $\mathrm{mW} / \mathrm{m}^{2}$. Both signal data and position information of the base stations were also recorded. For each mobile telecommunication operators, measurements were made of all active frequencies at each particular mobile measurement sampled location. The frequency considered in this research is between $900 \mathrm{MHz}$ and $2100 \mathrm{MHz}$ with the exposure limits listed in [7]. The point levels of measurement were recorded and evaluated against the ICNIRP exposure guidelines, which specifies a maximum non-occupational exposure limit of $4.50 \mathrm{~W} / \mathrm{m}^{2}$ at GSM 900 frequency band, $9.00 \mathrm{~W} / \mathrm{m}^{2}$ at GSM 1800 frequency band and $10.00 \mathrm{~W} / \mathrm{m}^{2}$ at UMTS 2100 frequency band [7].

The $\mathrm{RF}$ radiation was measured based on the four mobile telecommunication operators which are MTN, AIRTEL, GLO and ETISALAT within the coverage areas in the state. Also, the location of each base station was taken using a global positioning system (GPS). Thereafter the Peak and Average power density were calculated. Electric field strength was recorded at the height of 1.5 meter above ground level and with the with the dipole antenna in the vertical $(\mathrm{X})$, horizontal perpendicular $(\mathrm{Y})$ and horizontal aligned $(\mathrm{Z})$ orientation to the direction of the base station antenna. The combination of the polarized measurement gave the power density for each point of measurement. The power density was analyzed to give a total value of maximum power density from the base stations.

\subsection{Theoretical estimation of peak power density}

Using the Poynting theorem, the power density of the equivalent plane wave for time-harmonic EM fields is given [6-7] as:

$$
S=\frac{1}{2} \operatorname{Re}\left(\bar{E} \times \bar{H}^{*} \cdot \rho\right)=\frac{\left|E_{r m s}\right|^{2}}{Z_{o}}=Z_{\mathrm{o}}\left|H_{r m s}\right|^{2}
$$

where $\mathrm{S}$ is the power density in the distance $\rho\left(\mathrm{W} / \mathrm{m}^{2}\right), \rho$ is the distance from the antenna $(\mathrm{m}), \bar{E}$ is the electric field amplitude, $\bar{H}$ is the magnetic field amplitude and $Z_{\mathrm{o}}$ is the component of the electric field at a large distance from RF antenna. The power density emitted from a collinear antenna (far field) is estimated as given by (2), [6]:

$$
S=\frac{P_{T} G}{4 \pi \rho^{2}}
$$

where $P_{T}$ is the power from the transmitting antenna and $G$ is the antenna gain. 
The power density for the case of exposure to single BS as in Figure 1 at the exposed position (given by $\rho, \theta$, and $\varphi$ ) is given as:

$$
S=0.08 \frac{P_{T}}{\rho^{2}} 10^{\frac{G}{10}} \quad\left[\mathrm{~W} / \mathrm{m}^{2}\right]
$$

where $P_{T}$ is the transmitting antenna radiated power $(\mathrm{W})$, and $G$ is the gain of the antenna (dB).

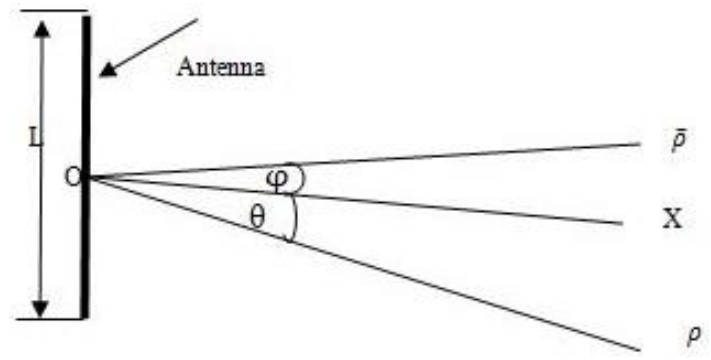

Figure 1. Collinear antenna and human exposure in the far field of a base station antenna [15]

The peak power density for a certain antenna in a given direction illustrated in Figure 1 can be calculated using (4). The highest values of the radiated power from antenna will be in the XO $\rho$ plane, taking to consideration that the down tilt is $90^{\circ}$ when the $\mathrm{XO} \rho$ plane is perpendicular with the centre $(\mathrm{O})$. At the distance " $\rho$ " (that has an azimuth angle $\varphi$ with OX direction), the peak power density can be computed using (4) $[15,17,22-24]$.

$$
\mathrm{S}^{\text {peak }}(\rho, \varphi)=\frac{W_{\text {rad }} 2^{-\left(\varphi / \bar{\varphi}_{3 \mathrm{~dB}}\right)^{2}}}{\bar{\varphi}_{3 \mathrm{~dB}} \rho L} \sqrt{1+2\left(\frac{\rho}{\rho_{0}}\right)^{2}}
$$

where $S^{\text {peak }}$ is the peak power density in $\mathrm{W} / \mathrm{m}^{2}, \bar{\varphi}_{3 \mathrm{~dB}}$ is the beam-width at $3 \mathrm{~dB}, W_{\text {rad }}=\eta \mathrm{P}_{\mathrm{in}}$; where $\eta$ is the antenna efficiency and $\mathrm{P}_{\text {in }}$ is the antenna connector input power. $\rho_{0}$ is calculated using (5) [24].

$$
\rho_{0}=\frac{\bar{\varphi}_{3 \mathrm{~dB}}}{6} D_{A} L
$$

where $\mathrm{D}_{\mathrm{A}}$ is the broad side directivity of the antenna and $L$ is the height of the antenna. The distance where the power density is equal to the ICNIRP limit known as the compliance distance is given as [17].

$$
\rho^{P e a k}=\rho\left(S^{P e a k}\right) \approx \rho_{0} \frac{2 \mathrm{q}}{\sqrt[4]{1+(4 q)^{2}}}
$$

where $q$ is calculated using (7):

$$
\mathrm{q}=\frac{3 W_{\text {rad }} 2^{-\left(\varphi / \bar{\varphi}_{3 \mathrm{~dB}}\right)^{2}}}{\bar{\varphi}_{3 \mathrm{~dB}} L^{2} D_{A} S^{\text {Peak }}}
$$

The value at $\varphi=0^{0}$ is the compliance distance for all calculation based on on the band of frequency band of operation. For Omni-directional antennas, the peak power density $\rho_{0}$ and $q$ given in (8) and (9) respectively.

$$
\begin{aligned}
& \rho_{0}=D_{A} L \\
& \mathrm{q}=\frac{W_{r a d}}{\pi L^{2} D_{A} S^{P e a k}}
\end{aligned}
$$

where $W_{\text {rad }}=\eta P_{\text {in }}, \eta$ is the antenna efficiency, $P_{\text {in }}$ is the antenna connector input power, $D_{A}$ is the directivity of the antenna, $\mathrm{L}$ is the height of the antenna and $S^{\text {Peak }}$ is the peak power density in W/m². 


\subsection{Theoretical estimation of average power density}

The average power density can be computed as [15]:

$$
\bar{S}(\rho, \varphi)=\frac{W_{\text {rad } 2}-\left(\varphi^{\varphi} \bar{\varphi}_{3 \mathrm{~dB}}\right)^{2}}{2 \bar{\varphi}_{3 \mathrm{~dB}} \rho L} \sqrt{1+\left(\frac{\rho}{\rho_{0}}\right)^{2}}
$$

while the compliance distance from Base Station Antenna then can be calculated as:

$$
\bar{\rho}=\rho(\bar{S}) \approx \rho_{0} \frac{\mathrm{q}}{\sqrt[4]{1+q^{2}}}
$$

In (10) and (11) can be employed to compute the power density radiation level and the compliance distance from the base stations $[19,25,26]$.

\section{RESULTS AND DISCUSSION}

\subsection{Measured values of the power density}

Tables 1, 2, and 3 summarizes the highest exposure levels recorded at each distance considered from Ado-Ekiti, Ifaki-Ekiti, and Iye-Ekiti base stations represented in $\mathrm{dBm}$ and $\mathrm{W} / \mathrm{m}^{2}$ as radiated by each mobile phone operator in different frequency bands. It can be observed from Table 1 that at 100 meters, GLO network has the highest radiation level of $22.89 \mathrm{~mW} / \mathrm{m}^{2}$, while at 20 meters MTN network has the least radiation level of $97.02 \mu \mathrm{W} / \mathrm{m}^{2}$ in all the three categories of cellular frequency bands considered. Table 2 shows that at 250 meters away from the mast, the AIRTEL network has the highest radiation level of $4.03 \mathrm{~mW} / \mathrm{m}^{2}$, while at 250 meters GLO network has the least radiation level of $10.39 \mu \mathrm{W} / \mathrm{m}^{2}$ in all the three categories of cellular frequency bands considered. It can be observed from Table 3 that at 20 meters away from the mast that AIRTEL network has the highest radiation level of $9.10 \mathrm{~mW} / \mathrm{m}^{2}$, while at 250 meters MTN network has the least radiation level of $8.58 \mu \mathrm{W} / \mathrm{m}^{2}$ in all the three categories of cellular frequency bands. Maximum RF Power density values measured in the 3 locations sampled and the maximum exposure limit as stipulated by ICNRIP are are as shown in Table 4 and compared with result from [17]. The result shows that the exposure limit is within the limit obtainable in Malaysia.

\begin{tabular}{|c|c|c|c|c|c|}
\hline $\begin{array}{l}\text { Distance from } \\
\text { mast }(\mathrm{m})\end{array}$ & $\begin{array}{c}\text { Frequency range } \\
(\mathrm{MHz})\end{array}$ & $\begin{array}{c}\text { MTN max. level } \\
\left(\mu \mathrm{W} / \mathrm{m}^{2}\right)\end{array}$ & $\begin{array}{c}\text { GLO max. level } \\
\left(\mu \mathrm{W} / \mathrm{m}^{2}\right)\end{array}$ & $\begin{array}{l}\text { AIRTEL max. level } \\
\left(\mu \mathrm{W} / \mathrm{m}^{2}\right)\end{array}$ & $\begin{array}{c}\text { ETISALAT max. level } \\
\left(\mu \mathrm{W} / \mathrm{m}^{2}\right)\end{array}$ \\
\hline \multirow{3}{*}{5.0} & $714-958$ & 9580.00 & 7560.00 & 1736.50 & 388.70 \\
\hline & $1500-1853$ & 2610.00 & 1797.20 & 1491.90 & 271.80 \\
\hline & $2035-2116$ & 173.30 & 1189.30 & 1223.30 & 308.00 \\
\hline \multirow{3}{*}{2.00} & 714-958 & 224.70 & 6730.00 & 498.00 & 220.70 \\
\hline & $1500-1853$ & 97.02 & 5750.00 & 317.00 & 178.50 \\
\hline & $2035-2116$ & 127.50 & 6520.00 & 417.30 & 745.50 \\
\hline \multirow{3}{*}{100.00} & 714-958 & 460.00 & 22890.00 & 735.00 & 27100.0 \\
\hline & $1500-1853$ & 282.00 & 7630.00 & 471.00 & 15300.00 \\
\hline & $2035-2116$ & 409.00 & 13160.00 & 554.30 & 18800.00 \\
\hline \multirow{3}{*}{250.00} & 714-958 & 1775.00 & 11680.00 & 813.00 & 964.30 \\
\hline & $1500-1853$ & 1011.00 & 2680.00 & 388.30 & 828.10 \\
\hline & $2035-2116$ & 1610.00 & 5960.00 & 583.00 & 877.10 \\
\hline
\end{tabular}

Table 1. Maximum RF radiations measured from Ado-Ekiti

\begin{tabular}{|c|c|c|c|c|}
\hline $\begin{array}{l}\text { Distance from mast } \\
(\mathrm{m})\end{array}$ & $\begin{array}{c}\text { Frequency range } \\
(\mathrm{MHz})\end{array}$ & $\begin{array}{c}\text { MTN max. level } \\
\left(\mu \mathrm{W} / \mathrm{m}^{2}\right)\end{array}$ & $\begin{array}{l}\text { GLO max. level } \\
\left(\mu \mathrm{W} / \mathrm{m}^{2}\right)\end{array}$ & $\begin{array}{c}\text { AIRTEL max. evel } \\
\left(\mu \mathrm{W} / \mathrm{m}^{2}\right)\end{array}$ \\
\hline \multirow{3}{*}{5.00} & $714-958$ & 811.20 & 423.30 & 2290.00 \\
\hline & $1500-1853$ & 566.20 & 194.40 & 2000.00 \\
\hline & $2035-2116$ & 741.50 & 342.00 & 2220.00 \\
\hline \multirow{3}{*}{20.00} & $714-958$ & 660.20 & 423.30 & 342.30 \\
\hline & $1500-1853$ & 228.40 & 161.10 & 186.40 \\
\hline & $2035-2116$ & 259.30 & 214.20 & 208.30 \\
\hline \multirow{3}{*}{100.00} & $714-958$ & 118.30 & 248.50 & 2280.00 \\
\hline & $1500-1853$ & 75.30 & 143.30 & 1916.60 \\
\hline & $2035-2116$ & 82.30 & 179.20 & 1945.20 \\
\hline \multirow{3}{*}{250.00} & $714-958$ & 860.60 & 75.70 & 4030.00 \\
\hline & $1500-1853$ & 100.70 & 10.39 & 1549.30 \\
\hline & $2035-2116$ & 747.30 & 15.60 & 2180.00 \\
\hline
\end{tabular}

Table 2. Maximum RF radiations measured from Ifaki-Ekiti

Radio frequency peak and average power density from mobile base... (Ilesanmi B. Oluwafemi) 
Table 3. Maximum RF radiations measured from Iye-Ekiti

\begin{tabular}{cccc}
\hline Distance from mast $(\mathrm{m})$ & Frequency range $(\mathrm{MHz})$ & MTN max. level $\left(\mu \mathrm{W} / \mathrm{m}^{2}\right)$ & AIRTEL max. level $\left(\mu \mathrm{W} / \mathrm{m}^{2}\right)$ \\
\hline \multirow{2}{*}{5.00} & $714-958$ & 858.70 & 4400.00 \\
& $1500-1853$ & 322.90 & 127.68 \\
\multirow{2}{*}{20.00} & $2035-2116$ & 558.20 & 201.30 \\
& $714-958$ & 4.85 & 9100.00 \\
\multirow{2}{*}{100.00} & $1500-1853$ & 246.50 & 67.40 \\
& $2035-2116$ & 282.50 & 133.20 \\
& $714-958$ & 1037.80 & 1609.50 \\
250.00 & $1500-1853$ & 209.30 & 202.90 \\
& $2035-2116$ & 282.05 & 201.30 \\
& $714-958$ & 1445.30 & 150.00 \\
& $1500-1853$ & 8.58 & 24.40 \\
\hline
\end{tabular}

Table 4. Maximum RF radiations

\begin{tabular}{cccc}
\hline Location & Maximum RF $\left(\mathrm{W} / \mathrm{m}^{2)}\right.$ & $\begin{array}{c}\text { \% Max radiation compared } \\
\text { with ICNIRP }\end{array}$ & $\begin{array}{c}\text { (\%) Radiation level compared } \\
\text { with ICNIRP from Malaysia [17] }\end{array}$ \\
\hline Ado & $(22.89 \pm 1.14) \times 10^{-3}$ & 0.23 & $0.05-0.82$ \\
Ifaki & $(4.03 \pm 0.20) \times 10^{-3}$ & 0.04 & $0.02-0.33$ \\
Iye & $(9.10 \pm 0.46) \times 10^{-3}$ & 0.2 & $0.07-0.89$ \\
\hline
\end{tabular}

\subsection{Computed values of the peak and average power density}

Huawei models are employed as the sector BSA in Nigeria. We considered the Huawei BSA model AMB452000 with 4 vertical dipoles to calculate the theoretical level of human exposure. The data from the manufacturer of these antennas are: frequency of emission $948.21 \mathrm{MHz}$; the gain, $19.2 \mathrm{dBi}$; the horizontal half power beam width, $\bar{\varphi}_{3 d B}=95.0^{\circ}, 1.66 \mathrm{dBi}$; the horizontal directivity, $18.0 \mathrm{dBi}$ and antenna dimensions $(\mathrm{H} \times \mathrm{W} \times \mathrm{D}) 1468 \times 349 \times 166(\mathrm{~mm})$. The radiative distance is taken as $\rho \approx 5.25 \mathrm{~m}$, and the far field distance start from $\rho \approx 10.57 \mathrm{~m}$ from antenna panel. From (3), and given that $\rho_{0}=2.56 \mathrm{~m}, h=50 \mathrm{~m}$ above the ground, and $G=-11.0 \mathrm{~dB}, \mathrm{~W}_{\mathrm{rad}}=16.0 \mathrm{~W}$, the theoretical power density $S_{\text {theor }}=3.50 \mathrm{~W} / \mathrm{m}^{2}$ for a person positioned on the ground at $(\rho, \theta, \varphi)=\left(20 \mathrm{~m}, 60^{\circ}, 30^{\circ}\right)$. This power density level is below the standard limit of ICNIRP.

For the near field exposure the average and peak power densities is calculated as $\bar{S}=0.2788 \mathrm{~W} / \mathrm{m}^{2}$ and $S^{p e a k}=0.4165 \mathrm{~W} / \mathrm{m}^{2}$ respectively for a person at $(\rho, \theta, \varphi)=\left(5 \mathrm{~m}, 60^{\circ}, 30^{\circ}\right)$ and $h^{\prime}=6.93 \mathrm{~m}$ under the antenna horizontal plane using (9) and (3). Comparing with the maximum limits of the average power densities given in the IEEE standard, which is $\bar{S}_{\max }=6.0 \mathrm{~W} / \mathrm{m}^{2}$ for uncontrolled conditions (population) and $\bar{S}_{\max }=30.0 \mathrm{~W} / \mathrm{m}^{2}$ for controlled conditions (professional) at $f=900 \mathrm{MHz}$. It is obvious that the exposure due to this antenna is far below the limit set by ICNIRP and therefore poses no harmful threat to the inhabitant. For the peak power density, it is obvious that the computed values is less that the limit set by the ICNIRP which is, $S_{\mathrm{max}}^{\text {peak }}=4.5 \mathrm{~W} / \mathrm{m}^{2}$ (population) and $S_{\mathrm{max}}^{\text {peak }}=22.5 \mathrm{~W} / \mathrm{m}^{2}$ (occupational). In term of compliance distances based on average (IEEE standard) or peak power densities values (ICNIRP standard), using azimuth direction $\varphi=30^{0}$ we got $\bar{\rho}=6.79 \mathrm{~m}$ and $\rho^{\text {peak }}=5.58 \mathrm{~m}$ from the Huawei antenna.

\subsection{The peak power density compared to the limit of safety distance for occupational and public exposure levels}

Table 5 shows the values of $S^{\text {peak }} / \rho^{\text {peak }}$ for different sub-frequency band and applications in Ekiti State, Nigeria. Figures 2, 3, and 4 shows the plot of the results at various intervals ranging from $0.85 \mathrm{~m}$ to $153.04 \mathrm{~m}$ at the three frequencies sub-bands of $900 \mathrm{MHz}, 1800 \mathrm{MHz}$ and $2100 \mathrm{MHz}$. Figure 2 shows the compliance distance for $900 \mathrm{MHz}$ application compared to the ICNIRP limits. The compliance distance is computed as $1.43 \mathrm{~m}$ and $3.75 \mathrm{~m}$ for occupational and public exposures respectively. In Figure 3 the compliance distance is shown for the $1800 \mathrm{MHz}$ application. It can be observed that the compliance distance is $1.03 \mathrm{~m}$ and $2.61 \mathrm{~m}$ for occupational and public exposures respectively. Figure 4 shows the compliance distance at $2100 \mathrm{MHz}$ applications. The compliance distance is seen to be $0.92 \mathrm{~m}$ and $2.46 \mathrm{~m}$ for occupational and public exposure respectively. It was discovered that there is no erected residential building within this compliance distance. In fact, the compliance distance is still within the perimeter fence of the base station considered. 
Table 5. Values of $S^{\text {peak }} / \rho^{\text {peak }}$ for different sub-frequency band in Ekiti State, Nigeria

\begin{tabular}{cccccc}
\hline S/N & Application & $\begin{array}{c}\text { Frequency } \\
(\mathrm{MHz})\end{array}$ & $\begin{array}{c}\text { ICNIRP for public } \\
\left(\mathrm{W} / \mathrm{m}^{2}\right)\end{array}$ & $\begin{array}{c}\text { ICNIRP occupational } \\
\left(\mathrm{W} / \mathrm{m}^{2}\right)\end{array}$ & $\begin{array}{c}\rho^{\text {peak }} \text { for } \\
\text { public/occupational(m) }\end{array}$ \\
\hline 1. & GSM 900 & 900 & 4.50 & 22.50 & $3.71 / 1.43$ \\
2. & GSM 1800 & 1800 & 9.00 & 45.00 & $2.61 / 1.03$ \\
3. & UMTS 2100 (3G) & 2100 & 10.00 & 50.00 & $2.46 / 0.92$ \\
\hline
\end{tabular}

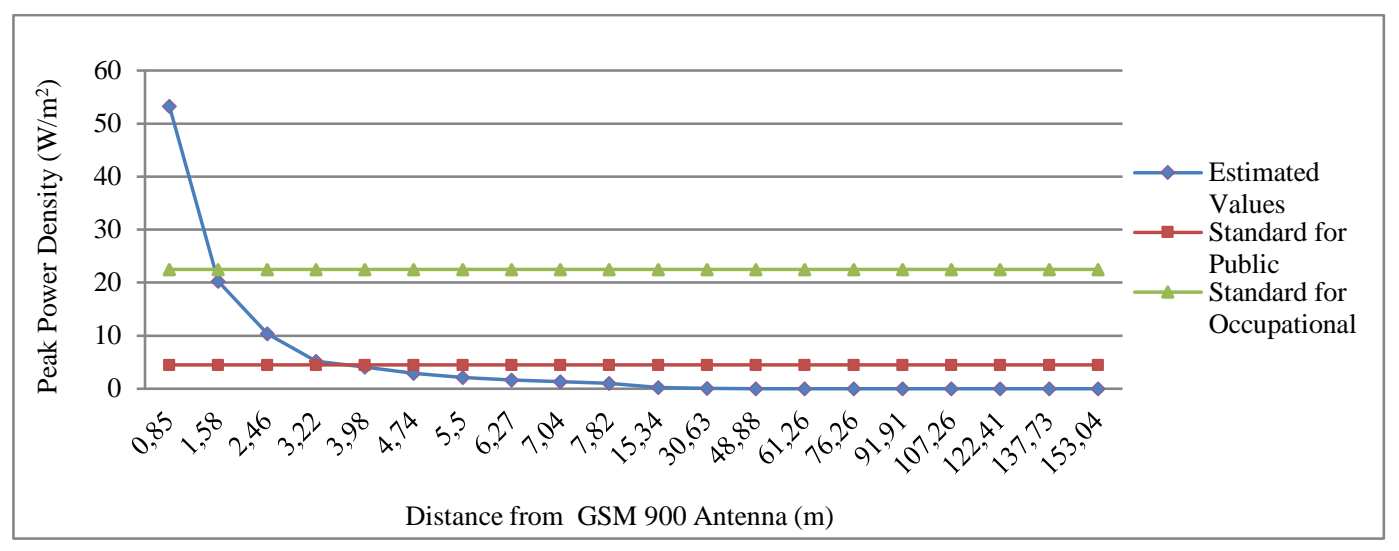

Figure 2. Compliance distance at $900 \mathrm{MH}$

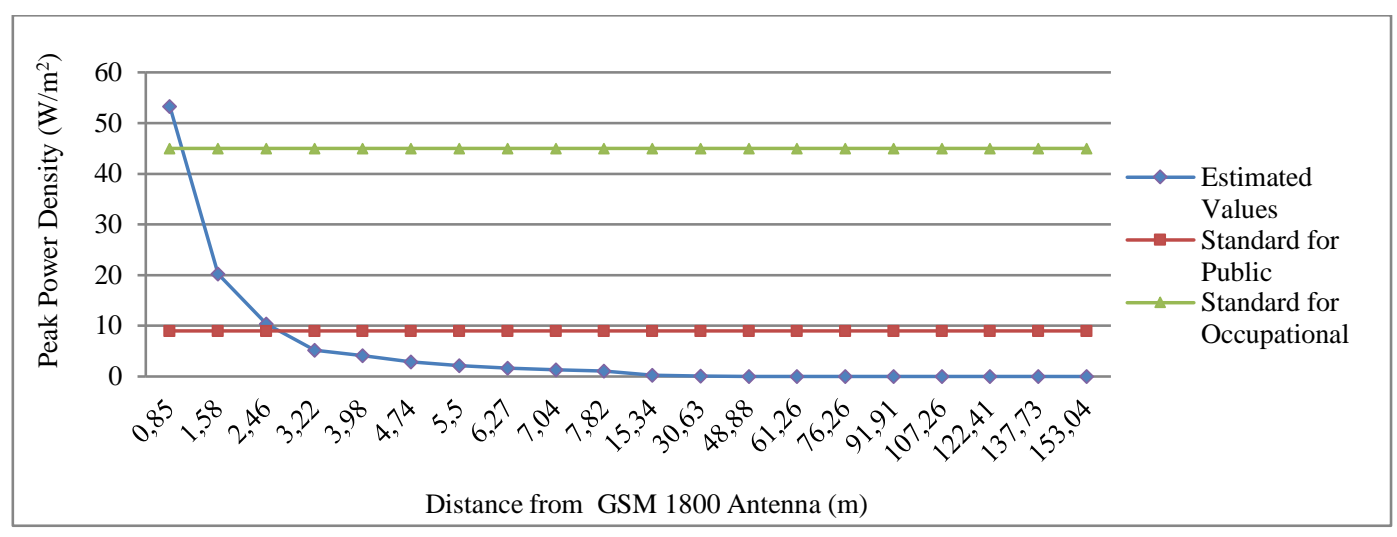

Figure 3. Compliance distance at $1800 \mathrm{MHz}$

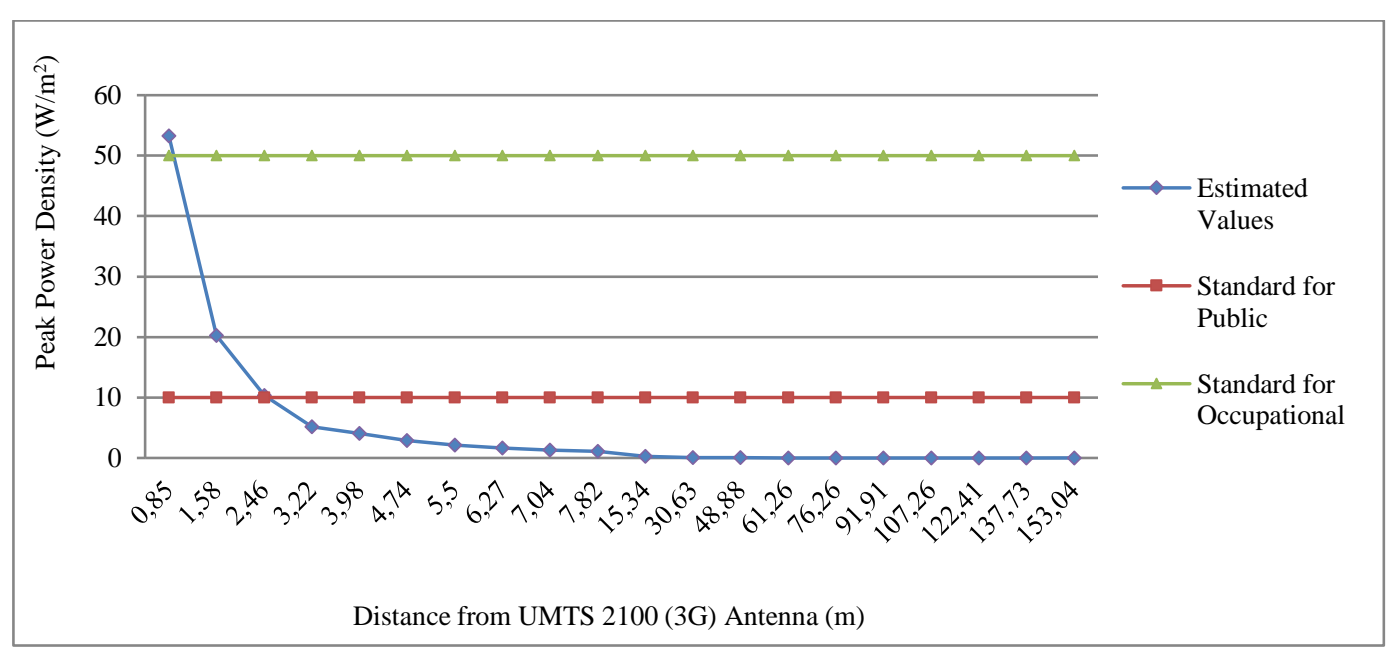

Figure 4. Compliance distance at $2100 \mathrm{MHz}$ 


\section{CONCLUSION}

There is increase in the usage of mobile phone as a communication medium and information source. The increase in the usage has led to increased in the number of mobile base station erection in Ekiti state. The increase has led to concern among the dwellers about the possible health effect of the exposure to the radio frequency radiations from these base stations as there are no significant information on the compliance of the radiation from the base station to the level recommended by the ICNIRP. Measurements were taken involving $900 \mathrm{MHz}, 1800 \mathrm{MHz}$ and $2100 \mathrm{MHz}$ operating base stations. The value of the power density radiation is obtained to be $0.23 \%$ of the maximum exposure level set by ICNIRP at $2100 \mathrm{MHz}$. At $900 \mathrm{MHz}$, the maximum power density is $0.04 \%$ of the limit while at $900 \mathrm{MHz}$ the power density is $0.2 \%$ of the safety limit of ICNIRP. Results from the measurement confirms that the level of RF radiation is very low and a few percentages of the limit set by the ICNIRP. The values of the theoretically computed power density are also less than the safety limit. The values of the measured and computed power density are very small compared to the international standard limits of (ICNIRP) for the public and occupational standard respectively. Therefore, the erected base stations in Ekiti State operating at the 900, 1800, and $2100 \mathrm{MHz}$ frequency band poses no threat to the health of the dwellers of Ekiti state.

\section{ACKNOWLEDGEMENTS}

The authors are appreciative to the Tertiary Education Trust Fund (TETFUND) for making fund available for the research through the Institution Base Research (IBR) fund.

\section{REFERENCES}

[1] Y. J. I. A. Yaqoob, W. L. Pang, S. K. Wong, and K. Y. Chan, "Performance evaluation of video streaming on LTE with coexistence of Wi-Fi signal," Bulletin of Electrical Engineering and Informatics, vol. 8, no. 3, pp. 890-897, 2019.

[2] I. B. Oluwafemi, "Hybrid concatenated coding scheme for MIMO systems," International Journal of Electrical and Computer Engineering, vol. 5, no. 3, pp. 464-476, 2015.

[3] I. B. Oluwafemi and S. H. Mneney, "Hybrid concatenated super-orthogonal space-time frequency coded MIMO-OFDM systems," Research Journal of Applied Science, Engineering and Technology, vol. 8, no. 4, pp. 530-540, 2014.

[4] I. B. Oluwafemi and S. H. Mneney, "Improved super-orthogonal space-time trellis coded MIMO-OFDM system" IETE Journal of Research, vol. 59, no. 6, pp. 665-671, 2013.

[5] I. B. Oluwafemi and S. H. Mneney, "Review of space-time coded OFDM system for wireless communication systems," IETE Technical Review, vol. 30, no. 5, pp. 417-426, 2013.

[6] A. Ozovehe, A. U. Usman, and A. Hamdallah, "Electromagnetic radiation exposure from cellular base station: A concern for public health," Nigerian Journal of Technology, vol. 34, no. 2, pp. 355-358, 2015.

[7] International Commission on Non-Ionizing Radiation Protection, "Guidelines for limiting exposure to time-varying electric, magnetic, and electromagnetic fields (up to $300 \mathrm{GHz}$ )," Health Physics, vol. 74, no. 4, pp. 494-522, 1998.

[8] A. Ismail, N. M. Din, M. Z. Jamaludin, and N. Balasubramaniam, "Mobile phone base station radiation study for addressing public concern," American Journal of Engineering and Applied Sciences, vol. 3, no. 1, pp. 117-120, 2010.

[9] A. A. Rahman and Jong Tze Kian, "Microwave radiation safety assessment near cellular base stations," 2005 1st International Conference on Computers, Communications, \& Signal Processing with Special Track on Biomedical Engineering, pp. 176-180, 2005.

[10] D. C. Yates, A. S. Holmes, and A. J. Burdett, "Optimal transmission frequency for ultralow-power short-range radio links," IEEE Transactions on Circuits and Systems I: Regular Papers, vol. 51, no. 7, pp. 1405-1413, 2004.

[11] M. A. Ahaneku, A. A. Nzeako, and N. N. Udora, "Investigation of electromagnetic radiations by GSM base stations in Nigeria for compliance testing," Advances in Physics Theories and Application, vol. 47, pp. 10-18, 2015.

[12] C. Olivier and L. Martens, "Optimal settings for narrow-band signal measurements used for exposure assessment around GSM base stations," IEEE Transactions on Instrumentation and Measurement, vol. 54, no. 1, pp. 311-317, Feb. 2005

[13] U. Bergqvist, G. Friedrich, Y. Hamnerius, L. Martens, G. Neubauer, G. Thuroczy, E. Vogel, and J. Wiart, "Mobile telecommunication base stations -exposure to electromagnetic fields," Report of a Short Term Mission within COST 244bis, COST 244bis Short Term Mission on Base Station Exposure, pp. 1-77, 2000.

[14] H. Lehmann, B. Eicher, and P. Fritschi, "Indoor measurements of the electrical field close to mobile phone base stations," 27th Triennial General Assembly of the International Union of Radio Science, 2002.

[15] B. Kamo, R. Miho, V. Kolici, S. Cela, and A. Lala, "Estimation of peak power density in the vicinity of cellular base stations, FM, UHF and WiMAX antennas," International Journal of Engineering \& Technology IJET-IJENS, vol. 11, no. 2, pp. 58-64, 2011

[16] A. Faraone, R. Yew-Siow Tay, K. H. Joyner, and Q. Balzano, "Estimation of the average power density in the vicinity of cellular base-station collinear array antennas," IEEE Transactions on Vehicular Technology, vol. 49, no. 3, pp. 984-996, May 2000.

[17] K. B. Khuzairi, H. Rahim, M. F. A. Malek, and M. Warip, "Radiofrequency radiation measurement for base tower station safety compliance: A case study in Pulau Pinang Malaysia," Bulletin of Electrical Engineering and Informatics, vol. 8, no. 1, pp. 150-157, 2019. 
[18] I. M. Fayed and E. S. El-Din, "Safety distance calculations for macrocell mobile base station and on site radiation measurements," 2017 European Conf. on Electrical Engineering and Computer Science (EECS), pp. 449-453, 2017.

[19] L. Hardell, M. Carlberg, and L. K. Hedendahl, "Radiofrequency radiation from nearby base stations gives high levels in an apartment in Stockholm, Sweden: A case report," Oncology Letters, vol. 15, no. 5, pp. 7871-7883, 2018.

[20] M. Carlberg, L. Hedendahl, T. Koppel, and L. Hardell, "High ambient radiofrequency radiation in Stockholm city, Sweden," Oncology Letters, vol. 17, no. 2, pp. 1777-1783, 2019.

[21] T. Koppel, M. Ahonen, M. Carlberg, L. K. Hedendahl, and L. Hardell, "Radiofrequency radiation from nearby mobile phone base stations-a case comparison of one low and one high exposure apartment," Oncology Letters, vol. 18, no. 5, pp. 5383-5391, 2019.

[22] R. Cicchetti and A. Faraone, "Estimation of the peak power density in the vicinity of cellular and radio base station antennas," IEEE Transactions on Electromagnetic Compatibility, vol. 46, no. 2, pp. 275-290, May 2004.

[23] R. Cicchetti, A. Faraone, and Q. Balzano, "A uniform asymptotic evaluation of the field radiated from collinear array antennas," IEEE Transactions on Antennas and Propagation, vol. 51, no. 1, pp. 89-102, Jan. 2003.

[24] S. M. Mann, T. G. Cooper, S. G. Allen, R. P. Blackwell, and A. J. Lowe, "Exposure to radio waves near mobile phone base stations Chilton," Didcot: NRPB report, 321, 2000.

[25] R. Miho and B. Kamo, "Estimation and theoretical evaluation of the E-M radiation field in the vicinity of GSM900 and GSM1800 antennas," VNM report for GSM900 and GSM1800, DET, FTI, Tirana, 2008.

[26] R. Miho and B. Kamo, "Estimation and theoretical evaluation of the E-M radiation field in the vicinity of 3G (2100MHz) antennas," VNM report for WiMAX 3, 2010.

\section{BIOGRAPHIES OF AUTHORS}
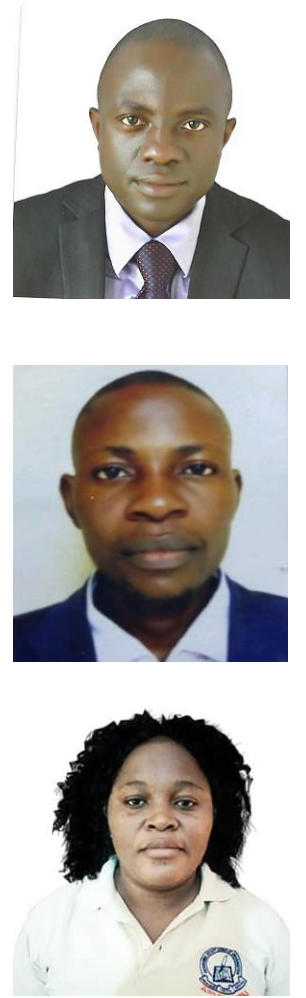

Ilesanmi B. Oluwafemi received the B.Eng degree in Electrical and Electronic Engineering from University of Ado Ekiti, Nigeria in 2000. He obtained the Master of Engineering degree in Electronic and Telecommunication from University of Benin, Nigeria in 2005 and Ph degree in Electronic Engineering at the school of Electrical, Electronic and Computer Engineering, University of KwaZulu-Natal, Durban, South Africa in 2012. He is currently a senior Lecturer in the Departent of Electrical and Electronic Engineering, Ekiti State University, Nigeria and the Research leader of the Center for Research in Electrical Communication (CRECO). His research interests are in the area of signal propagation, indoor power line communication wireless communication including space-time coding, channel coding, MIMO and OFDM systems

Matthew Adedeji Faluru received the Higher Diploma Degree in Electrical and Electronic Engineering from the Federal Polytechnic, Ado Ekiti Nigeria in the year 2002 and the Post graduate Diploma Degree in Electrical and Electronic Engineering from the Federal University of Technology, Akure Nigeria in 2009. He is currently studying for the degree of Master of Engineering in Electronic and Communication Engineeering in the Ekiti State University, Nigeria.

Tayo Doras Obasanya received the B.Eng in Electrical/Computer Engineering from Federal Uiversity of Technology, Minna in 2006 and M.Sc degree in Computer Science from Obafemi Awolowo University Ile-Ife in 2012. She is currently a lecturer in the Department of Computer Engineering, Ekiti State University, Ado Ekiti, Nigeria. Her research interest is in the area of Pervasive and mobile computing, internet of things and network security. 